\title{
Quantitative and Functional Analyses of Spastin in the Nervous System: Implications for Hereditary Spastic Paraplegia
}

\author{
Joanna M. Solowska, ${ }^{1}$ Gerardo Morfini, ${ }^{2}$ Aditi Falnikar, ${ }^{1}$ B. Timothy Himes,,${ }^{1,3}$ Scott T. Brady, ${ }^{2}$ Dongyang Huang, ${ }^{2}$ and \\ Peter W. Baas ${ }^{1}$ \\ ${ }^{1}$ Department of Neurobiology and Anatomy, Drexel University College of Medicine, Philadelphia, Pennsylvania 19129, ${ }^{2}$ Department of Anatomy and Cell \\ Biology, University of Illinois at Chicago, Chicago, Illinois 60612, and ${ }^{3}$ Department of Veterans Affairs Medical Center, Philadelphia, Pennsylvania 19104
}

\begin{abstract}
Spastin and P60-katanin are two distinct microtubule-severing proteins. Autosomal dominant mutations in the SPG4 locus corresponding to spastin are the most common cause of hereditary spastic paraplegia (HSP), a neurodegenerative disease that afflicts the adult corticospinal tracts. Here we sought to evaluate whether SPG4-based HSP is best understood as a "loss-of-function" disease. Using various rat tissues, we found that P60-katanin levels are much higher than spastin levels during development. In the adult, P60-katanin levels plunge dramatically but spastin levels decline only slightly. Quantitative data of spastin expression in specific regions of the nervous system failed to reveal any obvious explanation for the selective sensitivity of adult corticospinal tracts to loss of spastin activity. An alternative explanation relates to the fact that the mammalian spastin gene has two start codons, resulting in a 616 amino acid protein called M1 and a slightly shorter protein called M85. We found that M1 is almost absent from developing neurons and most adult neurons but comprises $20-25 \%$ of the spastin in the adult spinal cord, the location of the axons that degenerate during HSP. Experimental expression in cultured neurons of a short dysfunctional M1 polypeptide (but not a short dysfunctional M85 peptide) is deleterious to normal axonal growth. In squid axoplasm, the M1 peptide dramatically inhibits fast axonal transport, whereas the M85 peptide does not. These results are consistent with a "gain-of-function" mechanism underlying HSP wherein spastin mutations produce a cytotoxic protein in the case of M1 but not M85.
\end{abstract}

Key words: microtubule; neuron; axon; spastin; katanin; hereditary spastic paraplegia

\section{Introduction}

Hereditary spastic paraplegia (HSP) is a late-onset debilitating disease of the CNS that specifically afflicts the corticospinal tracts in the adult spinal cord. Mutations in SPG4, the gene that encodes for a protein called spastin, are the most common cause of HSP (Hazan et al., 1999; Salinas et al., 2007). Spastin is one of two well studied AAA ATPases expressed in vertebrate cells that sever microtubules (Errico et al., 2002). The other is called P60-katanin (McNally and Vale, 1993; Karabay et al., 2004; Yu et al., 2005). The severing of microtubules by these enzymes is functionally important for the axon. Within the axon, long microtubules are not highly mobile (Ma et al., 2004; Ahmad et al., 2006) and must

Received July 11, 2007; revised Dec. 19, 2007; accepted Jan. 8, 2008.

This work was supported by grants from the National Institutes of Health (NIH), the Spastic Paraplegia Foundation, the Alzheimer's Association, the Department of Defense, and the Craig H. Nielsen Foundation (P.W.B.), from the Amyloid Lateral Sclerosis Association and Huntington's Disease Society of America (G.M.), and from the NIH and Muscular Dystrophy Association (S.T.B.). We thank Elena Rugarli for providing us with human spastin constructs that were used for preliminary studies. We thank Wenqian Yu, Liang Qiang, Jed Shumsky, Douglas Baird, Bin Wang, Yuka Atagi, Katie Liu, Sarah Pollema, and Gustavo Pigino for advice, support, and technical assistance.

Correspondence should be addressed to either of the following: Peter W. Baas, Department of Neurobiology and Anatomy, Drexel University College of Medicine, 2900 Queen Lane, Philadelphia, PA 19129, E-mail: pbaas@drexelmed.edu; or Gerardo Morfini, Department of Anatomy and Cell Biology, University Of Illinois at Chicago, MC512, 808 South Wood Street, Room 578, Chicago, IL 60612, E-mail: gmorfini@uic.edu.

DOI:10.1523/JNEUROSCI.3159-07.2008

Copyright $\odot 2008$ Society for Neuroscience $\quad$ 0270-6474/08/282147-11\$15.00/0 be severed into shorter pieces before undergoing rapid transport (Wang and Brown, 2002; Baas and Qiang, 2005; Baas et al., 2005). Spatial control of microtubule severing is important for mobilizing large numbers of microtubules at growth-related locales such as the centrosome (Ahmad et al., 1999), sites of branch formation (Yu et al., 1994), and growth cones (Dent et al., 1999). In the adult, severing of microtubules need not be as robust as during development but is still required to ensure that a portion of the microtubule array remains mobile (Yu et al., 2007).

Most disease-related mutations of spastin render the protein dysfunctional and hence reduce the degree to which microtubules can be severed. In theory, this could lead to flaws in cytoskeletal organization and microtubule-based transport. At present, haploinsufficiency is the favored mechanism for the degeneration of axons in HSP, but there are several questions that cannot be easily answered by this mechanism (Zhao et al., 2001; Schickel et al., 2007). For example, there are no detectable flaws in neuronal development associated with the spastin mutations, despite the greater need for microtubule severing during development (Fink and Rainier, 2004). One possibility is that longer axons are more at risk than shorter axons, but this does not explain why peripheral neurons with long axons are unaffected. Another possibility is that the selective vulnerability of certain axons is related to the absolute 
levels of P60-katanin and spastin, given that these two proteins have overlapping properties.

Here, we quantitatively analyzed the absolute levels of each of the two microtubule-severing proteins in various regions of the rat nervous system during development and in the adult. These studies provided an unprecedented opportunity to assess the merits of a "loss-of-function" scenario for HSP. During the course of these studies, we discovered that the adult spinal cord contains significant levels of an isoform of spastin (termed M1), which is not readily detectable in any other nervous tissue at any other stage of life. On this basis, we conducted studies to determine whether pathogenic spastin peptides containing the sequence unique to M1 may have deleterious effects on the health of the axon. The results of these studies challenge the idea that HSP is best understood as a loss-of-function disease.

\section{Materials and Methods}

Preparation of spastin constructs and antibody. Mouse cDNA encoding full-length spastin was purchased from Invitrogen (Carlsbad, CA). Spastin constructs were generated by cloning mouse cDNA encoding spastin M1 (amino acids 2-614) and M85 (amino acids 86-614) into mammalian expression vector pCMV-Tag (Stratagene, La Jolla, CA) downstream from and in frame with the myc-tag. The vector provides a perfect Kozak consensus sequence and the first methionine encoding triplet: GCC GCCatgG for both $\mathrm{M} 1$ and $\mathrm{M} 85$ constructs. The M1 construct does not have $5^{\prime}$ untranslated region. $\Delta \mathrm{MIT}$ was generated as a construct starting at amino acid 192 so as to delete a domain called MIT, which is the "microtubule interacting and endosomal trafficking" domain (Claudiani et al., 2005; Roll-Mecak and Vale, 2005). To generate truncated M1 and M85 constructs for functional studies in squid axoplasm, plasmids were digested with $\mathrm{NcoI}$ restriction enzyme before in vitro transcription/translation. The constructs for functional studies in neuronal cells were prepared by cloning cDNA encoding the first 280 amino acids of $\mathrm{M} 1$ or the first 195 amino acids of M85 spastin into pEGFP-C vector (Clontech, Palo Alto, CA). These expressed proteins were termed M85-STOP and M1-STOP. To prepare a polyclonal antibody against spastin, a fragment of spastin cDNA encoding amino acids 337-465 was cloned into the bacterial expression vector pRSET (Invitrogen). A peptide termed SP/ AAA was purified, and a rabbit antiserum Sp/AAA was prepared by Cocalico Biologicals (Reamstown, PA). IgG fraction was purified by protein A-Sepharose chromatography. The specificity of the antibody was tested using mock-transfected cells, cells transfected with M1 or M85 spastin as positive controls, and cells transfected with P60-katanin as a negative control.

Quantitative Western blotting. For quantitative Western blotting, we calibrated the Sp/AAA antibody as described previously (Yu et al., 2005). We also used the polyclonal P60-katanin antibody that we previously generated, described, and calibrated (Karabay et al., 2004; Yu et al., 2005). To obtain standard curves, SDS-PAGE was performed using 10-60 fmol of purified M85 spastin or 20-200 fmol of purified, fulllength P60-katanin. After electrophoresis, proteins were transferred to nitrocellulose and immunoblotted with the anti-P60-katanin or the antispastin antibody (diluted 1:20,000). Optical density (OD) was measured for each protein band corresponding to different concentrations of spastin or P60-katanin, and standard curves were drawn. Rat neuronal tissues and non-neuronal tissues were isolated at different stages of development [embryonic day 18 (E18), postnatal day 0 (P0), P6, P12, and adult] and homogenized in Laemli's sample buffer using $1 \mathrm{ml}$ of buffer/100 $\mathrm{mg}$ of tissue (Yu et al., 2005). Protein extracts obtained from $1000 \mu \mathrm{g}$ of tissue from different developmental stages were used. One half of the extract was used for Western blotting with anti-spastin antibody, and the other half was used simultaneously for Western blotting with anti-P60-katanin antibody. After reaction with chemiluminescent peroxidase substrate (Super Signal; Pierce, New York, NY), each blot was covered with x-ray film. For OD readings, we used different exposure times from $5 \mathrm{~s}$ to 4 min. P60-katanin or spastin concentrations were read from standard curves drawn for each blot on which all sample proteins and standard proteins were visualized under identical conditions. Films were imaged using an Epson Perfection 1240U scanner. The optical densities were measured for bands corresponding to spastin and P60-katanin using a Macintosh computer (Apple Computers, Cupertino, CA) running NIH Image. Lysates of the RFL-6 cells (a rat lung fibroblast cell line) transfected with $\mathrm{M} 1$ and $\mathrm{M} 85$ recombinant myc-tagged spastin isoforms were used to indicate the molecular weight (MW) of spastins expressed in vivo. Myc-tag is 11 amino acids long, and there are three more amino acids added to spastin as a result of cloning. Altogether, this adds $\sim 1.7 \mathrm{kDa}$ to the recombinant spastins MW, and therefore the control recombinant M1 and M85 spastins migrate slightly above endogenous spastins.

Analysis of hypothetical loss of microtubule-severing activity attributable to spastin mutation. After having obtained values for the absolute levels of P60-katanin and spastin, we considered various possibilities for the loss of total microtubule-severing activity attributable to spastin mutations. It is unknown whether or not P60-katanin and spastin have equal severing activities within the axon, so these calculations enabled us to further evaluate the merits of a loss-of-function scenario for HSP. The absolute levels of P60-katanin and spastin expression in femtomoles were used to calculate the overall loss of microtubule-severing activity resulting from $50 \%$ reduction of spastin activity caused by mutations. For these analyses, we reasoned that, if the microtubule-severing activity of P60-katanin in vivo equals that of M85-spastin, then $1 \mathrm{fmol}$ of each protein represents one arbitrary microtubule-severing activity unit (AMSU) and therefore the total microtubule-severing activity equals expression of P60-katanin in femtomoles plus expression of spastin in femtomoles. However, if P60-katanin is twice as active as spastin, then $1 \mathrm{fmol}$ of P60-katanin would represent 2 AMSUs, and the total microtubule-severing activity equals two times expression of P60-katanin in femtomoles plus expression of spastin in femtomoles. In a situation in which M85-spastin is twice as active as P60-katanin, $1 \mathrm{fmol}$ of spastin would represent 2 AMSUs, and the total microtubule-severing activity equals expression of P60-katanin in femtomoles plus two times expression of spastin in femtomoles. Calculations were performed for spinal cord and hippocampus in the adult and at various developmental stages using the hypothetical ratios of P60-katanin/spastin activity 2:1, 1:1, 1:2, 1:4, and 1:10. The total microtubule-severing activity in spastin mutants equals the microtubule-severing activity calculated for P60-katanin plus one-half of the microtubule-severing activity calculated for spastin using different hypothetical ratios of P60-katanin/spastin activity. The overall loss of microtubule-severing activity was calculated by subtracting the percentage of activity left in mutant from $100 \%$ activity represented by wild-type tissue at a given developmental stage.

Preparation, transfection, and immunolabeling of cell cultures. Cultures of RFL- 6 rat fibroblasts were prepared and transfected with spastin constructs using lipofectamine 2000 (catalog \#11668-027; Invitrogen) as described previously (Buster et al., 2003). Primary rat cortical neurons were cultured and transfected (with the Amaxa nucleofector; Amaxa Biosystems, Gaithersburg, MD) using the identical approach to that which we used previously for cultured rat hippocampal neurons (Yu et al., 2005). For immunofluorescence studies, cells were fixed with $0.2 \%$ glutaraldehyde and $4 \%$ paraformaldehyde and then postextracted with $0.1 \%$ Triton X-100. In the case of the RFL-6 fibroblasts, the cultures were then double labeled by exposure first to anti-spastin Sp/AAA polyclonal antibody $(1: 10,000)$, overnight at $4^{\circ} \mathrm{C}$, and then to Alexa Fluor 488 conjugated goat anti-rabbit (catalog \#A11008; Invitrogen) and Cy3conjugated $\beta$-tubulin mouse monoclonal antibody for $1 \mathrm{~h}$ (at 1:500). Images were obtained on an Axiovert 200 microscope (Zeiss, Oberkochen, Germany) equipped with a high-resolution CCD (Orca ER; Hamamatsu, Hamamatsu City, Japan). Mean gray values (the sum of gray values of all the pixels in a selected cell divided by the number of pixels) were obtained using AxioVision software and presented as arbitrary fluorescence units (AFU). Cells with approximately equal levels of expressed protein were selected, and quantification was performed on the entire cell. In the case of the cortical neurons, the cells were transfected with the truncated green fluorescent protein (GFP)-spastin constructs or GFP control and then double-labeled for GFP and actin, as described previously (Yu et al., 2005). Double-label overlay images were obtained with a Zeiss Pascal LSM 5 confocal microscope (with the pin- 
hole wide open). For each experimental condition, neurons were scored according to the stage of development, and the length of the axon for neurons that had entered stage 3 of development was measured using Pascal LSM 5 software (Yu et al., 2005; Qiang et al., 2006). Statistics were done using Mann-Whitney $U$ test or $\chi^{2}$ test.

In vitro translation. For studies on vesicle motility in squid axoplasm, spastin polypeptides were produced by in vitro transcription/translation (TnT T7 coupled Reticulocyte Lysate system; Promega, Madison, WI), as described previously (Szebenyi et al., 2003; Morfini et al., 2006). Typically, $1-2 \mu \mathrm{g}$ of plasmids were transcribed in a $50 \mu \mathrm{l}$ reaction mix, following the procedures of the manufacturer. In vitro translation products were briefly centrifuged to eliminate translation machinery, and supernatants were frozen in liquid $\mathrm{N}_{2}$ until use. Spastin polypeptides were typically perfused at 1-10 nM levels. To ensure that the same levels of spastin peptides were perfused for each experimental condition, parallel reactions were performed using ${ }^{35}$ S-labeled methionine (GE Healthcare, Little Chalfont, UK), and relative levels were quantified using phosphoimaging scanning methods (Morfini et al., 2006).

Vesicle motility assays in isolated squid axoplasm. Axoplasm was extruded from giant axons of the squid Loligo pealeii (Marine Biological Laboratory, Woburn, MA) as described previously (Szebenyi et al., 2003; Morfini et al., 2006, 2007b). Axons were 400-600 $\mu \mathrm{m}$ in diameter and provided $\approx 5 \mu \mathrm{l}$ of axoplasm. Recombinant in vitro translated spastin peptides were diluted into X/2 buffer (in mM: 175 potassium aspartate, 65 taurine, 35 betaine, 25 glycine, $10 \mathrm{HEPES}, 6.5 \mathrm{MgCl}_{2}, 5 \mathrm{EGTA}, 1.5 \mathrm{CaCl}_{2}$, and 0.5 glucose, $\mathrm{pH} 7.2$ ) supplemented with $2-5 \mathrm{~mm}$ ATP. Twenty microliters of this mixture was added to perfusion chambers (Brady et al., 1993). Preparations were analyzed on a Zeiss Axiomat with a $100 \times, 1.3$ numerical aperture objective and differential interference contrast optics. Hamamatsu Argus 20 and model 2400 CCDs were used for image processing and analysis. Organelle velocities were measured with a Photonics Microscopy C2117 video manipulator (Hamamatsu). All experiments were repeated at least three times. Unless otherwise stated, the data were analyzed by ANOVA, followed by post hoc Student-Newman-Keuls test to make all possible comparisons.

\section{Results}

The functions of spastin were completely unknown until sequence homology with P60-katanin suggested that spastin might also be a microtubule-severing protein (Errico et al., 2002). The microtubule-severing properties of spastin have now been confirmed experimentally by overexpression of spastin in cells, as well as by application of recombinant spastin protein to purified microtubules and extracted cells (Errico et al., 2002; Evans et al., 2005; Roll-Mecak and Vale, 2005). However, it is unclear whether alterations in this activity are the principle cause of degeneration of a specific population of axons in the adult spinal cord during HSP. In addition, little is still known about the molecular forms of spastin expressed in different tissues or the relative contribution of spastin and P60-katanin to microtubule function in different neuronal populations.

The vertebrate spastin gene has two start codons that produce a long form and a shorter protein lacking the first 84 amino acids of the full-length protein (Claudiani et al., 2005). We refer to the full-length $68 \mathrm{kDa}$ spastin protein as $\mathrm{M} 1$ and the shorter $60 \mathrm{kDa}$ protein as M85 (Fig. 1A). We generated DNA constructs for mouse M1 and M85, both driven by strong promoters for use in our experimental studies. In addition, we made a construct starting at amino acid 192 so as to delete a domain called MIT, which is the "microtubule interacting and endosomal trafficking" domain (Claudiani et al., 2005; Roll-Mecak and Vale, 2005). We refer to this last construct as $\Delta \mathrm{MIT}$. We also generated constructs that produce truncated, HSP-related versions of M85 and M1 (see below).

To date, there have been no functional studies comparing the microtubule-severing properties of M1 and M85, nor have there
A
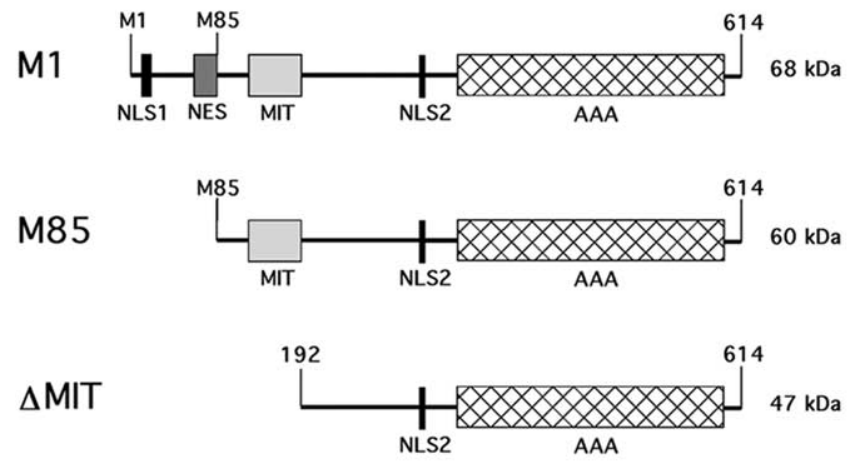

Ab SP/AAA

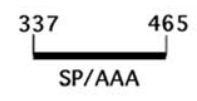

B

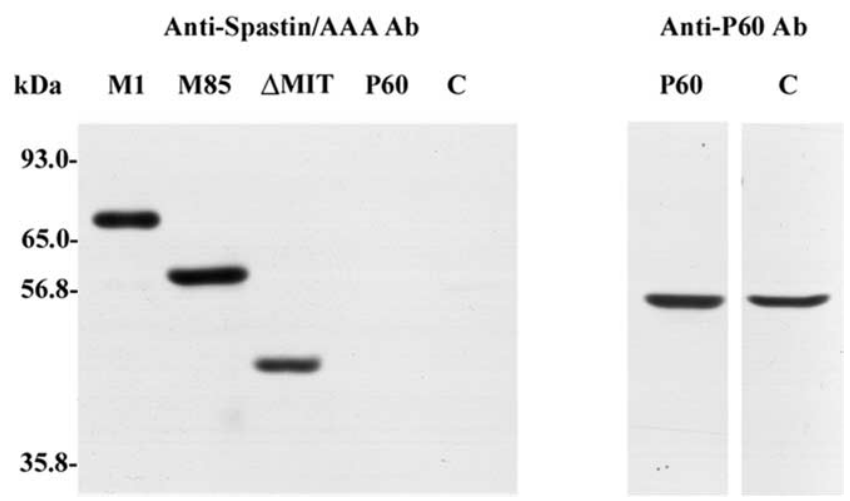

Figure 1. Mouse spastin constructs and antibody. A, Schematic diagram of full-length mouse spastin M1 derived from translation starting at methionine 1, M85 spastin derived from translation starting at methionine 85 , and $\Delta \mathrm{MIT}$, which corresponds to our construct that lacks the MIT domain. NLS1 and NLS2, Nuclear localization signals; NES, nuclear export signal; MIT, microtubule-interacting and trafficking domain; AAA, AAA domain; Ab Sp/AAA, anti-spastin antibody was prepared against amino acids 337-465. B. Detection of spastin with anti-spastin antibody Sp/AAA. M1 (68 kDa), M85 (60 kDa), or $\Delta \mathrm{MIT}(47 \mathrm{kDa})$ proteins were specifically detected in lysates from RFL-6 cells transfected with M1, M85, or $\Delta$ MIT spastin constructs. Sp/AAA antibody does not cross-react with P60-katanin in a lysate from P60-katanin (P60) transfected cells. Endogenous spastin was not detected in control RFL-6 cells using Sp/AAA antibody when concentration of total protein was comparable with that from transfected cells. When higher amounts of lysates were used, a $60 \mathrm{kDa}$ band corresponding to endogenous M85 spastin was detected (data not shown). P60-katanin was readily detected in both P60-katanin transfected (P60) and control RFL-6 cells with anti-P60-katanin antibody. C, Control lane.

been any quantitative studies on the levels of M1 and M85 in different regions of the nervous system at different stages of life. We previously performed quantitative analyses on the absolute levels of P60-katanin in adult and developing rat tissues (Yu et al., 2005). One of the stumbling blocks to performing analogous studies on spastin has been the lack of high-quality antibodies that can be used on rodent tissues. We have now developed a polyclonal antibody against amino acids 337-465 of mouse spastin (Fig. 1A). This antibody, which we call Sp/AAA, proved to be highly specific for spastin in our Western blot analyses. The antibody detected M1, M85, and $\Delta$ MIT spastin in lysates from RFL-6 cells transfected with corresponding spastin constructs (used as positive controls) but did not detect any band corre- 
sponding to P60-katanin in lysates obtained from RFL- 6 cells transfected with our P60-katanin construct (P60), used as a negative control (Fig. $1 B$ ). Interestingly, endogenous spastin expression in mocktransfected RFL- 6 cells (Fig. $1 B$, lane C), a non-neuronal cell line, is very low; detection of spastin in these cells required larger amounts of cell lysate than those sufficient to detect P60-katanin with the anti-P60katanin antibody.

\section{Evaluation of microtubule-severing by} M1, M85, and $\Delta$ MIT

Additional Western blotting, shown later, demonstrates that M85 is the predominant isoform of spastin in all tissues at all stages of development analyzed. This observation raised the question as to whether M1 and M85 differ in their functional properties. To compare their microtubule-severing properties, we transfected myc fusions of M1 and M85 into rat RFL- 6 fibroblasts. We also transfected these cells with the $\Delta$ MIT construct to compare the degree to which the protein severs microtubules with or without the MIT domain. At $24 \mathrm{~h}$ after transfection, the cells were prepared for immunofluorescence microscopy by double labeling with the Sp/AAA antibody and an anti-tubulin antibody. There was no detectable endogenous spastin in interphase RFL- 6 cells, so the staining with the Sp/AAA antibody revealed the overexpressed protein only (Fig. 2A). Cells were selected for analyses with approximately equivalent levels of expression of the spastin constructs, as assessed by fluorescence intensity of the Sp/AAA antibody staining. Microtubule levels were assessed by quantifying fluorescence intensity with an antitubulin antibody. This experiment revealed that all three of the recombinant spastins sever microtubules but to different degrees (Fig. $2 B-D$ ). The most effective was M85. Microtubule loss in cells overexpressing M85 was the greatest (only $\sim 10 \%$ of microtubule staining remained compared with the control cells, indicated by arrowheads; Fig. 2, row B). The remaining microtubules were very short and sparse, rendering the affected cells almost invisible after tubulin staining (Fig. 2, column M85). As previously reported (White et al., 2007), the absence of the MIT domain did not abolish the severing ability of spastin. However, microtubule severing was not as great with $\Delta$ MIT as with M85 ( $\sim 25 \%$ of microtubule staining remained, and the remaining microtubules were longer; Fig. 2, column $\Delta \mathrm{MIT})$. In cells overexpressing M1, $60 \%$ of the microtubule staining remained and the microtubules were considerably longer than those in cells expressing M85 or $\Delta$ MIT (Fig. 2, column M1). On the basis of these results, we conclude
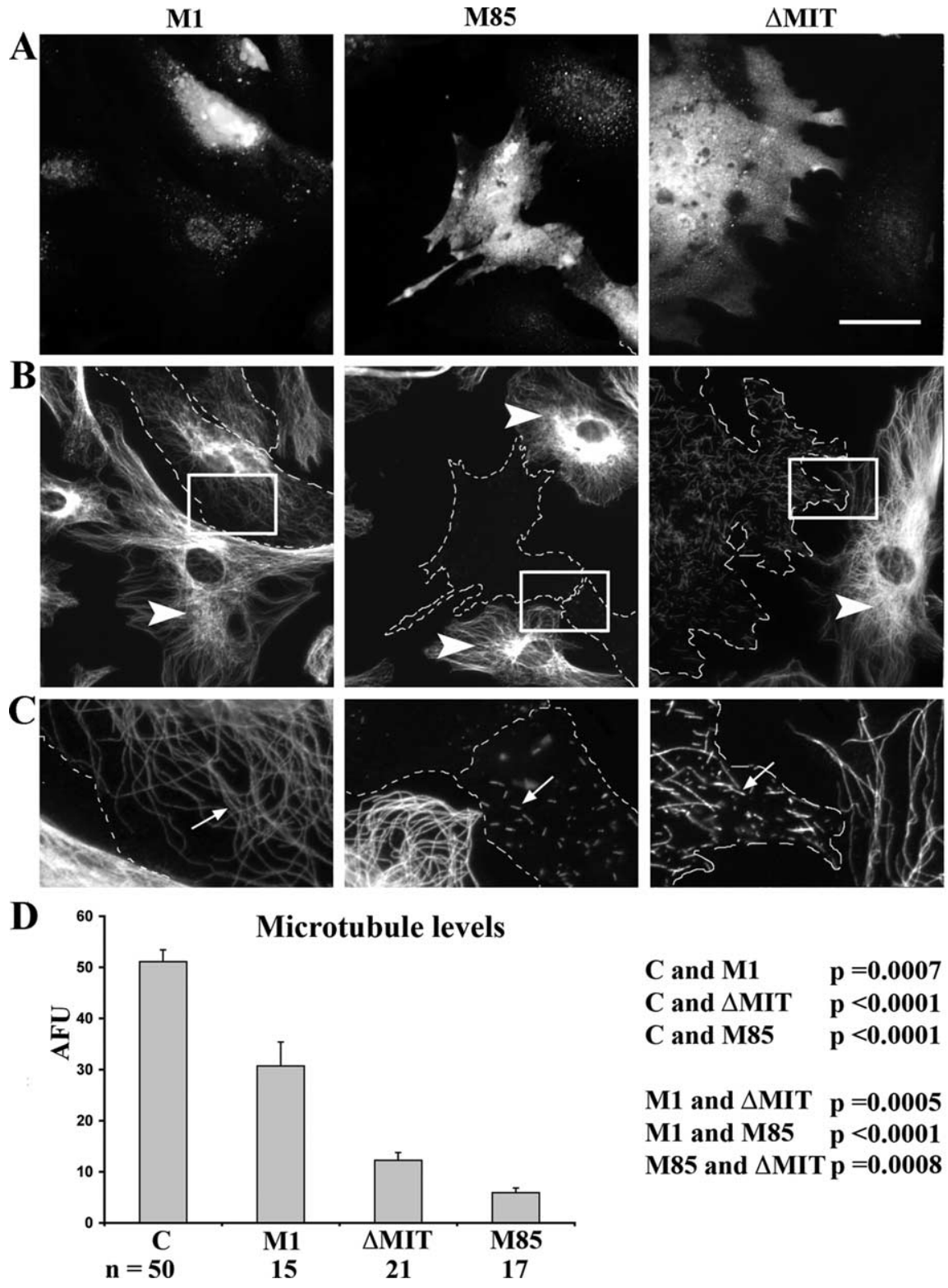

M1 and $\triangle$ MIT $p=0.0005$

M1 and M85 $\quad$ p $<0.0001$

M85 and $\triangle$ MIT $p=0.0008$

Figure 2. Microtubule severing by recombinant spastins in rat fibroblasts. RFL-6 cells were transfected with myc-tagged spastin constructs M1, M85, or $\Delta$ MIT. A, Spastin-transfected cells were detected by immunostaining with Sp/AAA anti-spastin antibody. $\boldsymbol{B}$, Microtubules were visualized by immunostaining with anti-tubulin antibody. Spastin-overexpressing cells are outlined. Nontransfected cells are indicated by arrowheads. These cells are not readily visible in $\boldsymbol{A}$ because of very low expression of endogenous spastin. $\boldsymbol{C}$, Enlargements of boxed areas from $\boldsymbol{B}$. Arrows point at microtubules stained with anti-tubulin antibody. Microtubules in M1-overexpressing cells are much longer than microtubules in M85-overexpressing or $\Delta$ MIT-overexpressing cells. D, Quantification of microtubule levels in control and transfected cells are shown for each recombinant spastin. The $p$ values were calculated using Mann-Whitney $U$ test. AFUs represent the sum of gray values of all the pixels in a selected cell divided by the number of pixels. Scale bar: $\boldsymbol{A}, \boldsymbol{B}, 30 \mu \mathrm{m} ; \boldsymbol{C}, 9.5 \mu \mathrm{m}$.

that M85 severs microtubules more effectively than M1 and that the MIT domain enhances the severing ability of spastin.

\section{Quantification of spastin and P60-katanin in rat tissues}

Patients with SPG4-based HSP have one mutated spastin allele that produces a dysfunctional protein, as well as one nonmutated allele. Assuming no compensatory changes exist, this would diminish the pool of functional spastin by $50 \%$. One possibility is that the total levels of both microtubule-severing proteins, P60katanin and spastin, determine whether a particular neuron will suffer or not from a reduction in functional spastin levels. Western blot analyses indicate that P60-katanin has a broad distribu- 
$\mathbf{A}$
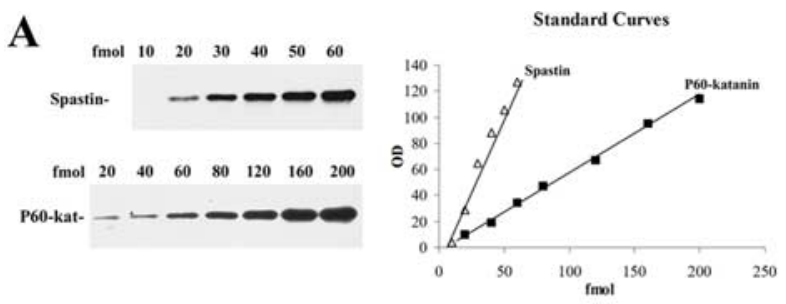

B

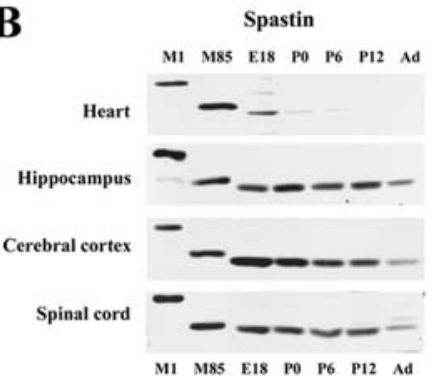

C

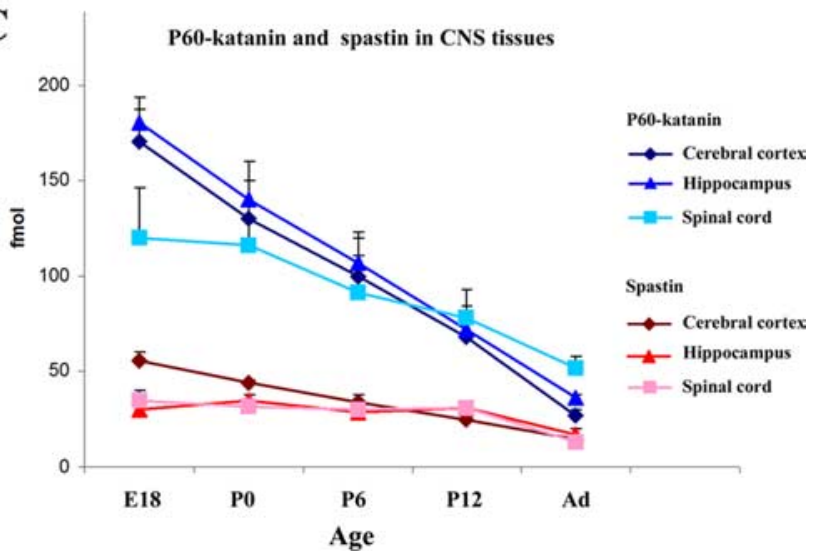

Figure 3. Quantification of P60-katanin and spastin in developing CNS tissues. A, Calibration of anti-spastin and anti-P60-katanin antibodies. Standard curves were obtained using $10-60$ fmol of spastin or 20-200 fmol of P60-katanin. $\boldsymbol{B}$, Western blots of spastin and P60-katanin in developing rat tissues. Tissues (heart, hippocampus, cerebral cortex, and spinal cord) were collected and combined from 12 E18 rats, eight P0 rats, six P6 rats, six P12 rats, and four adult (Ad) rats. Protein extracts from $1000 \mu \mathrm{g}$ of combined tissues in sample buffer were divided into halves. One half of the lysate was used for Western blotting with anti-spastin antibody, and the other half was blotted simultaneously with anti-P60-katanin antibody. The M1 and M85 recombinant myc-tagged spastin isoforms synthesized in RFL-6 cells transfected with corresponding constructs were used to indicate the MW of spastins expressed in developing tissues. Myc-tag adds $\sim 1.7 \mathrm{kDa}$ to the recombinant spastins MW (see Materials and Methods), and therefore the control recombinant M1 and M85 spastins migrate slightly above endogenous spastins. After short exposure (5-15 s), only M85 was detected. In heart (representing non-neuronal tissue), the levels of spastin expression were considerably lower than in CNS tissues. C, The optical densities were measured for bands representing M85 spastin or P60-katanin in neuronal tissues, and protein concentrations were read from standard curves. At each time point, expression of P60-katanin is higher than that of spastin, but, during development, P60-katanin levels decline much more rapidly than spastin levels. As a result, the total difference in P60-katanin/ spastin expression decreases from $\sim 130 \mathrm{fmol} / 500 \mu \mathrm{g}$ in embryonic CNS tissues to $\sim 25 \mathrm{fmol} /$ $500 \mu \mathrm{g}$ in adult tissues.

tion across neuronal and non-neuronal tissues (Yu et al., 2005), whereas spastin expression is much more predominant in nervous tissue compared with non-nervous tissue (Fig. 3B). The lack of strong expression in non-nervous tissues is consistent with these tissues not being affected by spastin mutations. Additionally, our Western blots analyses show that M85 is the predominant spastin isoform detected in all tissues at all times analyzed
(Fig. 3B). Quantitative analysis of these blots shows that the absolute levels of P60-katanin always exceed the absolute levels of spastin, with P60-katanin levels being fivefold to sixfold higher than spastin levels in some areas of the nervous system during development. The levels of both severing proteins decline in the adult, but the levels of P60-katanin decline more dramatically than the levels of spastin, so that the disparity between their levels is not nearly as great in the adult as during development (Fig. 3C).

At first glance, these results would appear to be consistent with a loss-of-function scenario for HSP, in which high levels of P60katanin compensate for the loss of spastin at younger ages and in most tissues of the adult nervous system. In such a scenario, the combined levels of P60-katanin and spastin would not be sufficient in the adult corticospinal tracts to compensate for the lossof-functional spastin associated with disease-related mutations. However, the level of microtubule severing produced by each of these proteins depends not only on the absolute levels of P60katanin and spastin but also on the relative severing activity of the two enzymes. Both proteins are ATPases that require ATP hydrolysis to sever microtubules. The $V_{\max }$ (nanomoles of ATP hydrolyzed per minute per milligram of ATPase) values obtained for both proteins is in the same range: 0.60 for P60-katanin (McNally and Vale, 1993) and 0.66 for spastin (Evans et al., 2005). In vitro, the ability to sever purified microtubules seems to be higher for P60-katanin. For example, $\sim 30 \mathrm{~nm}$ P60-katanin completely disassembled rhodamine-labeled microtubules within $5 \mathrm{~min}$ (McNally and Vale, 1993), whereas $100 \mathrm{~nm}$ spastin was used for 17 min to observe the same effect (Evans et al., 2005). However, it is important to note that the spastin used in these experiments was the M1 isoform, which our experiments indicate is less active than the M85 isoform (Fig. 2). Thus, it is likely that the in vitro severing activity of M85 spastin (which is the predominant isoform) is more similar to that of P60-katanin. Evaluation of the in vivo microtubule-severing activity of $\mathrm{P} 60$-katanin and spastin is further complicated by the fact that microtubules in living cells are covered with microtubule-associated proteins, some of which can potentially shield the microtubules from the severing proteins (Qiang et al., 2006).

Given these limitations in determining the actual severing activities of P60-katanin and spastin in living cells, we conducted theoretical analyses considering various possibilities for the relative severing activities of these two proteins (see Materials and Methods). Specifically, our goal was to estimate how different hypothetical ratios of $\mathrm{P} 60$-katanin and M85-spastin activity would affect total microtubule-severing activity in various tissues, under conditions wherein a spastin mutation decreased the total spastin activity by $50 \%$. These calculations are based on the levels of P60-katanin and M85-spastin in various regions of the nervous system at various times in development (Fig. 3). The estimated percentage loss of total microtubule-severing activity resulting from a 50\% loss of M85-spastin is shown in Figure 4. Calculations were performed for spinal cord and hippocampus in the adult and at various developmental stages, using various hypothetical ratios of P60-katanin/spastin activity $(2: 1,1: 1,1: 2,1: 4$, and $1: 10)$. These calculations revealed that, regardless of the P60katanin/spastin activity ratio, the loss of total microtubulesevering activity resulting from a spastin mutation would actually be similar or even lower in the adult spinal cord than in developing spinal cord or hippocampus (with the exception of E18 hippocampus).

These results do not appear to support a loss-of-function scenario for HSP, unless the axons in the adult spinal cord are uniquely sensitive to diminutions in microtubule-severing activ- 


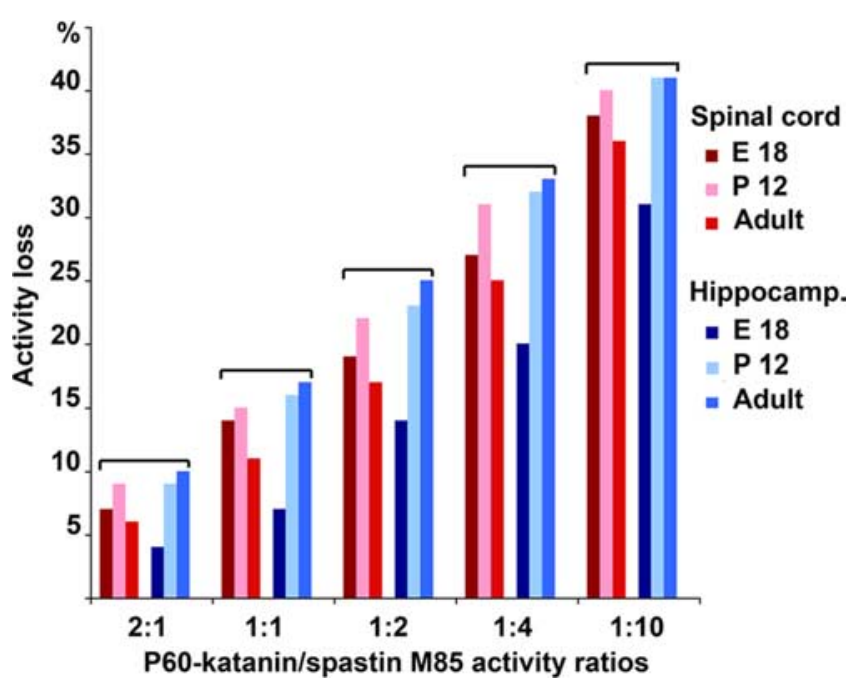

Figure 4. Estimated loss of total microtubule-severing activity attributable to spastin M85 mutation. These analyses are based on the levels of P60-katanin and M85 spastin in various regions of the nervous system at various times of development presented in Figure 3. Calculations were performed for both spinal cord and hippocampus in the adult and at different developmental stages using the hypothetical ratios of P60-katanin/spastin activity 2:1, 1:1, 1:2, 1:4, and 1:10. The loss of total severing activity resulting from spastin mutation would not be greater in an adult spinal cord than in a developing spinal cord or hippocampus (with the exception of E18 hippocampus). Even if we assume that spastin is 10 times as active as P60-katanin, the loss of total severing activity in adult spinal cord would be $<40 \%$. Assuming a more realistic scenario wherein spastin might be two times as active as $\mathrm{P} 60$-katanin, a total loss of microtubulesevering activity would be only $17 \%$ in adult spinal cord. If spastin and P60-katanin activities were equal (1:1), then the loss of activity resulting from spastin mutation would be only $\sim 11 \%$ in adult spinal cord.

ity that do not affect axons in the developing spinal cord or other regions of the nervous system (perhaps because of the greater length of axons in the adult spinal cord). However, even if we assume that spastin is 10 times as active as P60-katanin, the loss of total severing activity in adult spinal cord would be $<40 \%$. Assuming that P60-katanin and spastin activities are equal, then the loss of activity resulting from spastin mutation would be only $\sim 11 \%$ in adult spinal cord. In a more realistic scenario, assuming that spastin might be two times as active as P60-katanin, a total loss of microtubule-severing activity would be only $17 \%$ in adult spinal cord. To our knowledge, there is no precedent for neuropathologies resulting from diminutions in enzyme activities in this range, given that virtually all known enzymatic activities exceed what is needed for normal function. In this regard, it is also worth noting that the concentration of P60-katanin alone in neuronal tissues is in the same range as the concentration able to cause complete disassembly of microtubules in vitro within minutes. Thus, it seems unlikely that neurons lacking half their normal spastin would suffer from too little microtubule-severing activity.

Quantitative observations on M1 and M85 distribution suggest another potential scenario for HSP pathogenesis. Overexposing the blots (Fig. 5A) revealed extremely faint M1 bands in hippocampus and cerebral cortex but only during development. However, there was no M1 band, even on overexposed blots, in the adult hippocampus, the adult cerebral cortex, or the developing spinal cord. The only circumstance in which we detected a substantial M1 band in the nervous system was in the adult spinal cord. We tested three adult animals, 3-8 months old, and found that the level of M1 expression remains approximately the same and comprises $\sim 20-25 \%$ of total spastin (and would be equiva- lent to $\sim 10 \%$ of P60-katanin) in the adult spinal cord (Fig. $5 B-$ $D)$. At the same time, we were unable to detect even traces of M1 or M85 in sciatic nerves isolated from the same animals (Fig. 5B). In contrast, $\mathrm{P} 60$-katanin levels were comparable in adult sciatic nerves and spinal cords (Fig. 5C). The absence of spastin from the adult sciatic nerve suggests that spastin may be primarily a CNS protein in the adult, which is consistent with the fact that HSP does not involve degeneration of axons of the peripheral nervous system. The presence of M1 strongly correlates with the time and place where the axonal degeneration occurs in HSP, suggesting a possible "gain-of-function" mechanism associated with this spastin isoform.

\section{Effects of dysfunctional spastin peptides on neuronal morphology}

The biochemical studies presented thus far led us to hypothesize a potential scenario whereby dysfunctional M1, but not M85, elicits deleterious effects on the axon. Approximately $75 \%$ of the disease-related mutations of human SPG4 locus are truncating or splice-site mutations (Fonknechten et al., 2000; Meijer et al., 2002; Sauter et al., 2002). Therefore, as a first measure toward testing this hypothesis, we prepared constructs that would mimic the dysfunctional mutants expressed during HSP by completely eliminating the AAA region of spastin required for microtubule severing (see Materials and Methods). For studies on cultures of embryonic rat cortical neurons, M85-STOP and M1-STOP were prepared as GFP fusion constructs. We chose to use these cultures because cortical neurons give rise to the corticospinal tracts that are afflicted with degeneration in HSP patients. In culture, these neurons undergo stereotyped developmental stages, entirely similar to cultured hippocampal neurons (Yu et al., 2005; Qiang et al., 2006). During stage 1, they extend broad flat lamellae that coalesce during stage 2 into several immature "minor processes." One of these minor processes grows longer than the others and becomes the axon during stage 3. Constructs expressing GFPM85-STOP, GFP-M1-STOP, or GFP alone were transfected into the neurons just before plating, and the neurons were then fixed and analyzed $2 \mathrm{~d}$ later. Cultures were double labeled for GFP and also for actin. The purpose of the actin stain was to ensure that our images captured the full morphology of the neuron, in the event that the GFPs were not distributed into all regions such as the finest filopodia. We attempted to select neurons with similar levels of GFP fluorescence for our analyses, although the neurons expressing GFP-M1-STOP uniformly showed lower levels of expression than the neurons expressing GPP alone or GFP-M85-STOP.

As shown in Figure $6 A$, the proportions of cells in stages 2 and 3 were indistinguishable between the control group and the M85STOP group ( $p=0.76$ ). In contrast, a notably greater proportion of the cells have not entered stage 3 in the M1-STOP group ( $p=$ 0.0033 for control vs M1-STOP cells in stage 3; $p=0.0074$ for M85-STOP vs M1-STOP cells). Figure $6 B-D$ shows the morphology of neurons that had entered stage 3. Control neurons typically had three to six minor processes, and the axon generally showed a few branches along its length and was tipped by a flat growth cone (Fig. 6B). Neurons expressing M85-STOP appeared to be equally robust, with no apparent difference in process number or length. The only detectable difference was that axons of neurons expressing M85-STOP appeared to be richer in actinbased lateral extensions emanating from the axon (Fig. 6D). In contrast, the neurons expressing M1-STOP had markedly less impressive morphologies, with fewer processes and shorter axons (Fig. 6C). Quantification of axonal length indicated no difference 
A

Hippocampus

M1 M85 E18 P0 P12 Ad

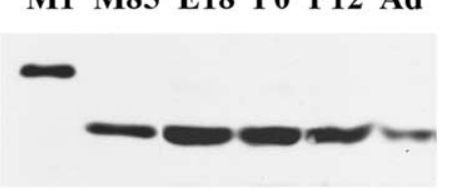

Cerebral cortex

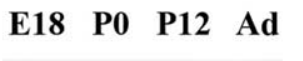

\section{Spinal cord}

E18 P0 P12 Ad

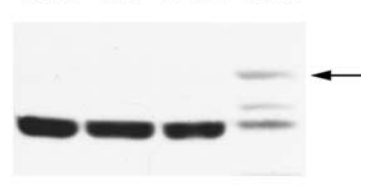

B
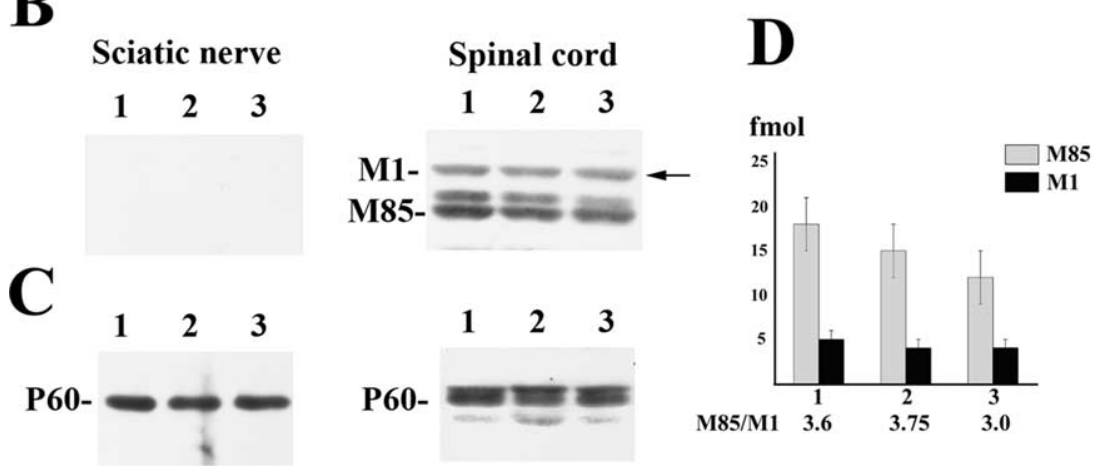

Figure 5. Expression of spastin isoforms in neuronal tissues. $\boldsymbol{A}$, Western blots of spastin in developing and adult rat CNS tissues. Spastin isoforms were detected in protein extracts from $500 \mu \mathrm{g}$ of tissues using anti-spastin Sp/AAA antibody and secondary antibody conjugated with HRP. After reaction with chemiluminescent peroxidase substrate and long exposure time (2 min), prominent spastin M85 bands were detected in CNS tissues at all developmental stages, but only adult spinal cord expressed strong levels of spastin M1 (arrow). Very weak spastin M1 bands were detected in embryonic but not adult hippocampus and cerebral cortex. M1, M85, Spastin isoforms from M1- or M85-transfected RFL-6 cells indicate the size of spastin present in developing tissues; Ad, adult. B, Sciatic nerve or spinal cord protein extracts from three rats, $3-8$ months old, were blotted with anti-spastin Sp/AAA antibody. Even after long exposure (4 min), no spastin was detected in three adult sciatic nerve lysates, whereas both M85 and M1 spastin were clearly present in lysates from adult spinal cords. C, Aliquots blotted with anti-P60katanin antibody show that P60-katanin is expressed in both adult sciatic nerves and spinal cords. D, Quantification of M85 and M1 spastin in spinal cords of 3-month-old (1), 7-month-old (2), and 8-month-old (3) rats.

between axons in the control group and the M85-STOP group ( $p=0.1)$, but the axons were significantly shorter in the M1STOP group $(p=0.0024$ compared with controls; $p<0.0001$ compared with M85-STOP) (Fig. 6E). These results reveal that expression of M1-STOP is deleterious to neuronal development and axonal growth, whereas the same is not true for expression of M85-STOP.

\section{Effects of dysfunctional spastin peptides on fast axonal transport}

Previous studies on mutant proteins related to other neurodegenerative diseases indicate that such mutants can produce gainof-function effects by adversely affecting pathways relevant to fast axonal transport (FAT) (Morfini et al., 2002, 2004, 2005, 2006, 2007b; Pigino et al., 2003). Significantly, several lines of evidence link alterations in FAT to HSP-based pathogenesis. For example, loss-of-function mutations in the kinesin-1 motor KIF5A have been identified in patients with an autosomal-dominant form of HSP (Reid et al., 2002). To directly determine whether there is an effect of the dysfunctional spastin molecules on FAT, wild-type and truncated spastin constructs were translated in vitro (Fig. $7 A$ ), and the effects of the resulting peptides on FAT were evaluated using vesicle motility assays in isolated squid axoplasm. In this type of study, video-enhanced microscopic techniques allow for the quantitative analysis of both anterograde (kinesindependent) and retrograde (cytoplasmic dynein-dependent) FAT. Typical anterograde rates are $1.5-2.0 \mu \mathrm{m} / \mathrm{s}$, whereas retro- grade rates are $1-1.3 \mu \mathrm{m} / \mathrm{s}$ in perfused axoplasms. These rates are maintained with little $(<10 \%)$ or no reduction for $>1$ $\mathrm{h}$ after perfusion with control buffer.

Although control reactions with no cDNA did not result in detectable protein synthesis, two functional start codons in the full-length spastin gene (Spastin FL) resulted in the translation of M1 (spastin amino acids 1-614) and M85 (spastin amino acids 85-614), as described previously (Fig. 7A) (Claudiani et al., 2005). As shown in Figure $7 B$, perfusion of fulllength M1 and M85 (Spastin FL) in squid axoplasm showed no effect on FAT. Similar results were observed after perfusion of $\Delta$ MIT (Fig. $7 C$ ). Quantification of in vitro translated spastin constructs indicated that these proteins were perfused at $\sim 1-10$ nM concentration, whereas endogenous squid tubulin is present at $50 \mu \mathrm{M}$ concentration (Morfini et al., 2007a). No abnormalities were seen on the morphology of axoplasmic microtubules (Morfini et al., 2007a), consistent with the large difference (5000-fold to 50,000-fold) in spastin-tubulin stoichiometries (data not shown). The very low concentrations we used were chosen so as to avoid any consequential alterations in microtubule severing in the controls and because concentrations of mutant peptides in this range have produced defects in FAT at comparable levels in the previous studies mentioned above.

Perfusion of the mixture of M1-STOP and M85-STOP in squid axoplasm at these levels resulted in a striking inhibition of both anterograde and retrograde FAT rates (Fig. $7 D$ ). These data suggest that pathogenic spastin inhibits FAT in a manner that is independent of the microtubule-severing activity of spastin. Additionally, these experiments suggest that protein truncation confers on spastin a toxic gain of function that results in inhibition of FAT. Separate pools of M1-STOP and M85-STOP were then generated by in vitro translation and individually perfused in isolated squid axoplasm (Fig. 8). Results from these experiments showed that truncated M1 inhibited FAT (Fig. 8A), whereas truncated M85 showed no effect (Fig. $8 B$ ). These results indicate that the inhibitory effect of pathogenic spastin on FAT depends on the $\mathrm{N}$-terminal $8 \mathrm{kDa}$ region exclusively present in M1 spastin.

\section{Discussion}

The present studies are the first to quantify the absolute levels of both P60-katanin and spastin in the nervous system. During development, the levels of P60-katanin are many times higher than the levels of spastin, but the levels of the two proteins are not as different in the adult attributable to a notable plunge in the levels of P60-katanin. It makes sense that the total levels of the two severing proteins are higher during development because the need for microtubule transport and reorganization is presumably much greater when the axon is growing. The fact that spastin mutations in humans result in no developmental abnormalities suggests that the high levels of P60-katanin are able to fully compensate for the diminished levels of spastin. Indeed, a transgenic 
mouse lacking functional spastin shows no detectable flaws in development (Tarrade et al., 2006). However, these neurons show some abnormalities when cultured, and some zebrafish neurons display abnormalities in axonal growth when spastin levels are diminished using morpholinos (Wood et al., 2006). These observations suggest that P60-katanin is capable of compensating for spastin under most circumstances but that the two severing proteins are not completely identical with regard to their functions and how they are regulated. We are currently conducting studies to further explore this possibility. For now, our goal was to evaluate potential mechanisms underlying axonal degeneration resulting from spastin mutations.

Detailed analyses of spastin mutations identified to date do not reveal an obvious candidate pathogenic mechanism for HSP (Fink, 2006; Schickel et al., 2007). Most of $>150$ human disease-related spastin mutations are nonsense, frame-shift, or splice-site mutations that presumably encode truncated spastin molecules lacking the AAA domain. Approximately 25\% of spastin mutations are missense mutations falling within the AAA cassette. Because these various mutations would produce a dysfunctional protein unable to sever microtubules, the prevalent view has been that SPG4-based HSP is most probably a loss-of-function disease, with degeneration of axons resulting from affected neurons not reaching a hypothetical threshold of microtubule severing (Svenson et al., 2001; Errico et al., 2002). The main purpose of our quantitative Western blot analyses was to test the viability of this scenario. Consistent with the late-onset characteristic of HSP, we found that developing neurons contain far more P60katanin than adult neurons, and hence developing neurons would be far better equipped to compensate for reductions in functional spastin levels associated with SPG4 mutations. In light of our tissue distribution studies, the lack of degeneration of long peripheral axons observed in HSP also makes sense, because adult peripheral neurons appear to express no spastin whatsoever and hence would be dependent on P60-katanin for microtubule severing.

At present, it is unknown whether equal amounts of P60katanin and spastin have the same or different microtubulesevering activities in the axon. With regard to P60-katanin, its severing activity can be dampened by the presence of microtubule-associated proteins on the microtubules (Buster et al., 2002; Qiang et al., 2006) but enhanced by the presence of a cofactor termed P80-katanin (Hartman et al., 1998; Yu et al., 2005). Whether or not spastin is similarly regulated remains to be

A

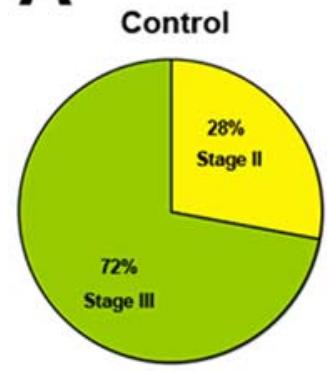

M85 STOP
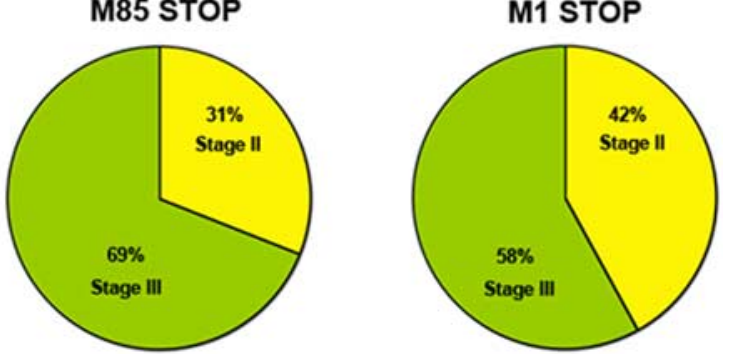
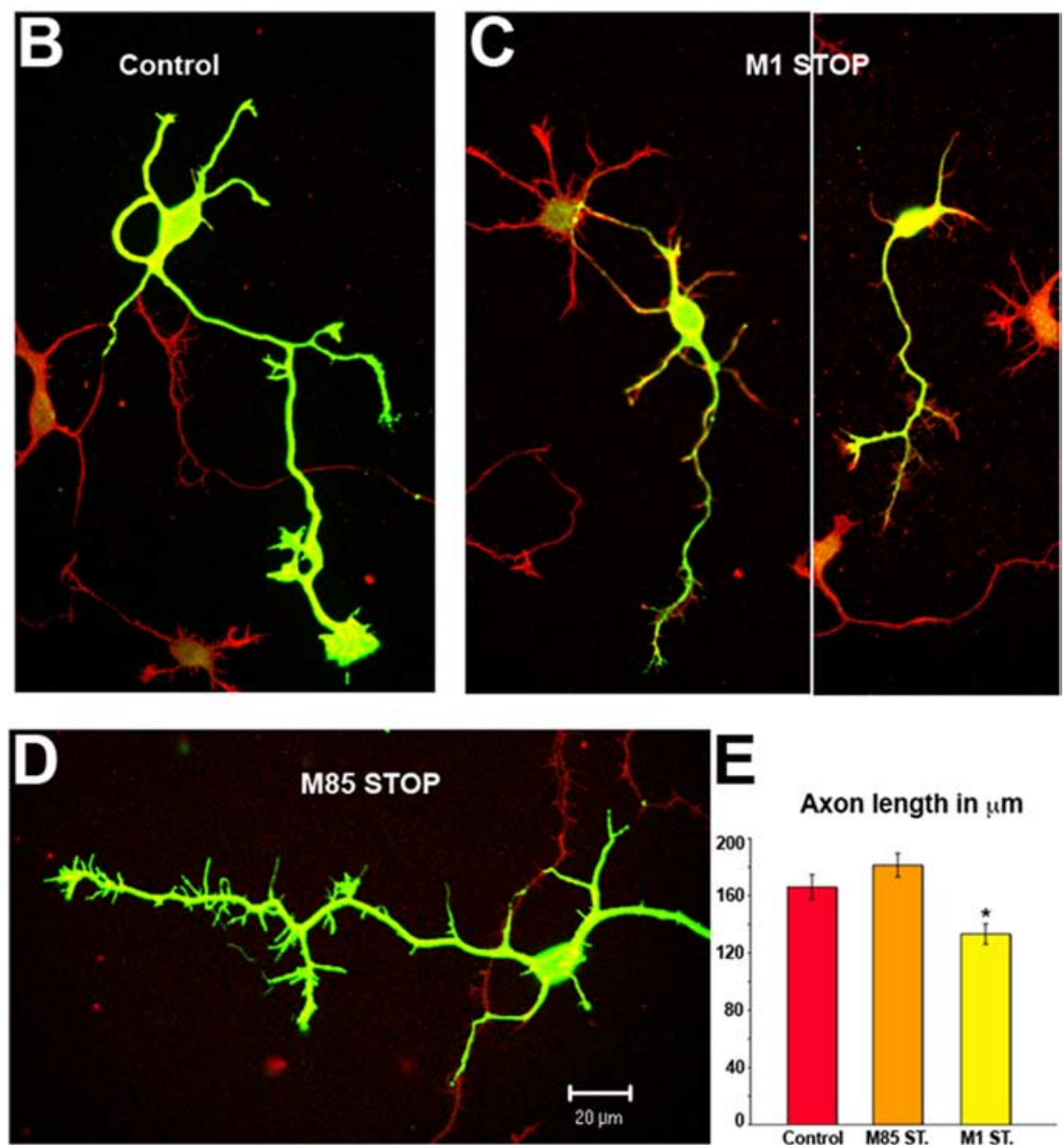

Axon length in $\mu \mathrm{m}$

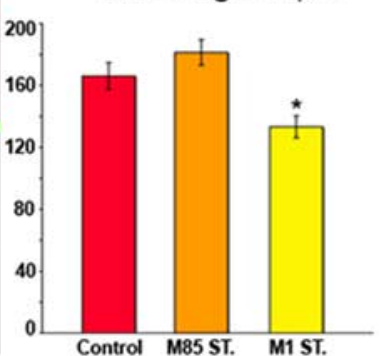

Figure 6. Effects of dysfunctional spastins on neuronal morphology. A, A total of 302,350 , and 272 cortical neurons transfected, respectively, with control GFP construct, GFP-M85-STOP, and GFP-M1-STOP were examined and classified as stage 2 or stage 3 neurons. The quantitative analysis revealed no significant differences between the control and M85-STOP groups. In contrast, the M1-STOP group was delayed in development compared with the other two groups. $\boldsymbol{B}-\boldsymbol{D}$, Transfected cortical neurons were double labeled for GFP (green) and actin (red). The control group $(\boldsymbol{B})$ and the M85-STOP group (D) show a morphology more robust than the M1-STOP group (C). The M85-STOP group was somewhat different from the control group in that it displayed more actin-rich lateral extensions along the length of the axon. $\boldsymbol{E}$, The M1-STOP group $(n=52)$ had significantly shorter axons than the control group $(n=57)$ or the M85-STOP group $(n=60)(p=0.0024$ and $p<0.0001$, respectively). There was no difference in axonal length between the control group and the M85-STOP group ( $p=0.1052$ ). All error bars represent SEM.

tested. Whatever the relative microtubule-severing activity of the two proteins may be in vivo, our calculations indicate no obvious scenario that can explain why a $50 \%$ loss of spastin activity would reduce the overall microtubule-severing activity in the adult spinal cord to a greater extent than in other regions of the adult or developing nervous system. Thus, the only apparent way to reconcile our data with a loss-of-function scenario for HSP is to posit that the health of particularly long CNS axons is more sen- 

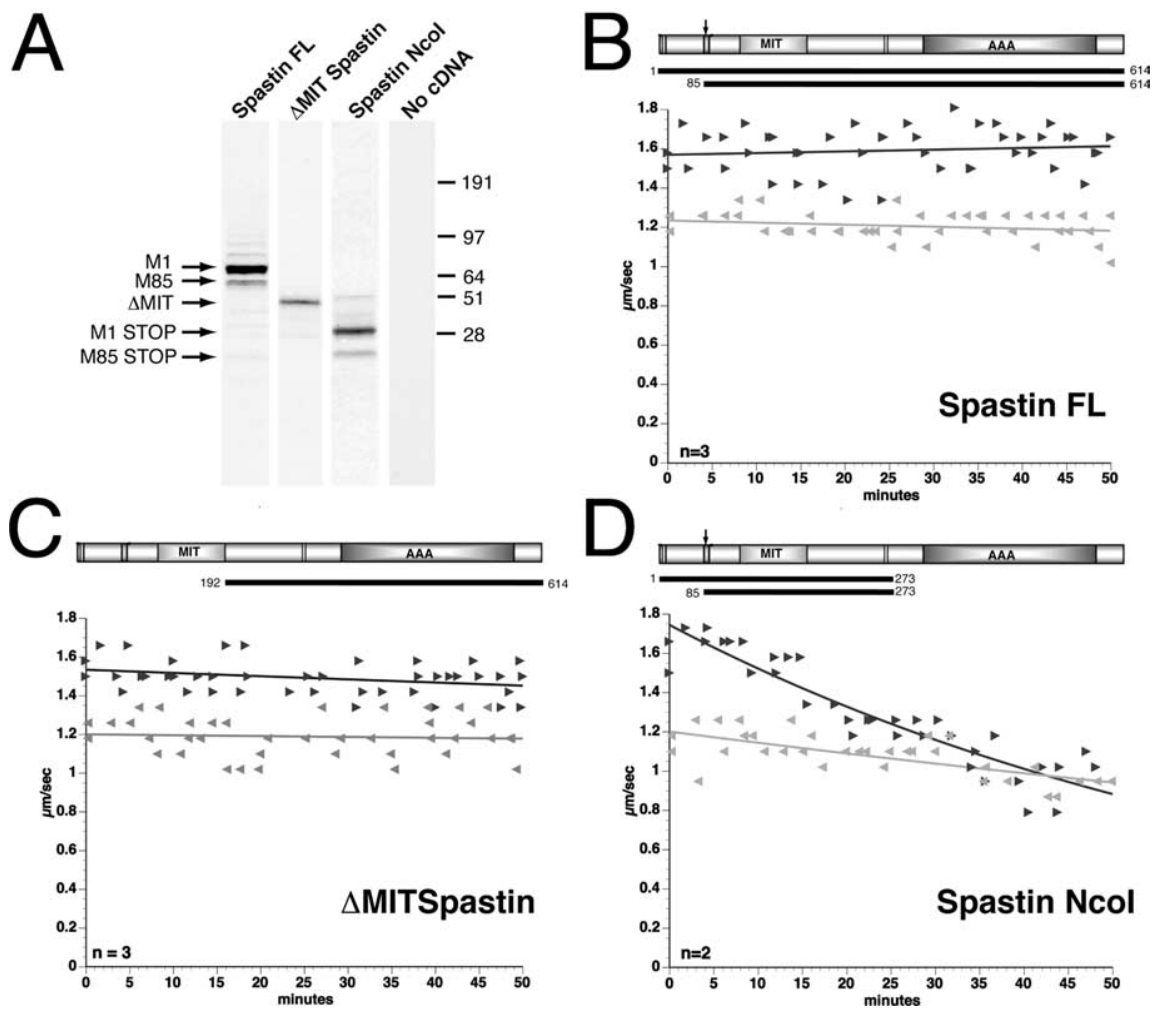

Figure 7. Effects of wild-type and truncated spastin peptides on fast axonal transport. $\boldsymbol{A}$, Autoradiogram showing in vitro translated, $\left[{ }^{35}\right.$ S]methionine-labeled spastin constructs used for squid axoplasm perfusion experiments. The presence of two functional start codons in the mammalian full-length spastin cDNA construct (Spastin FL) results in the production of both $68 \mathrm{kDa}$ (M1 spastin, amino acids 1-616), and $60 \mathrm{kDa}$ (M85 spastin, amino acids 85-616) spastin products when translated in vitro. Digestion of full-length spastin plasmid with $\mathrm{NcOl}$ (Spastin Ncol) before in vitro translation results in the synthesis of $29 \mathrm{kDa}$ (M1-STOP, amino acids 1-273) and $21 \mathrm{kDa}$ (M85-STOP, amino acids 85-273) truncated spastin polypeptides. The spastin construct lacking the MIT domain (spastin $\triangle$ MIT, amino acids 192-614) was also effectively translated. Control reactions (no cDNA) did not result in detectable protein synthesis. $\boldsymbol{B}-\boldsymbol{D}$, Vesicle motility assays in isolated squid axoplasm. Individual velocity measurements (arrowheads) are plotted as a function of time. Anterograde (dark arrows and line) and retrograde FAT (reverse gray arrows and line) rates are shown. In vitro translated control reactions as shown in $A$ were perfused in axoplasm, and FAT rates were monitored by video microscopy. A schematic depicting spastin constructs perfused for each experiment is also shown above each plot. Both MIT and AAA spastin domains are indicated. An arrow at amino acid position 85 indicates the second start codon that gives raise to M85. $\boldsymbol{B}, \boldsymbol{C}$, Perfusion of either full-length spastin or $\triangle$ MIT spastin peptides did not affect FAT rates. $\boldsymbol{D}$, However, perfusion of truncated spastin Ncol polypeptides significantly inhibited FAT rates in both directions. $n$ indicates the number of independent experiments.
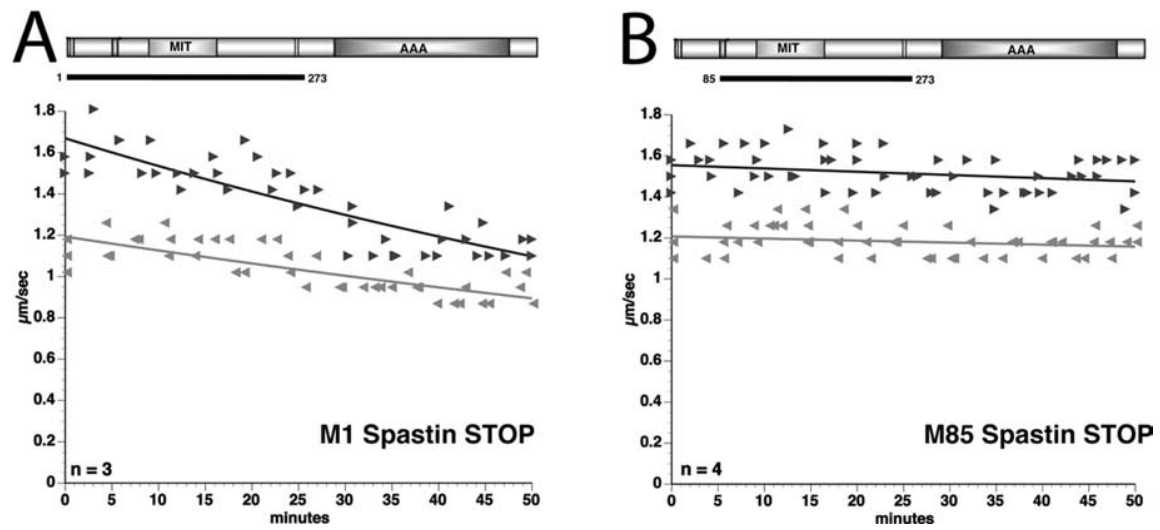

Figure 8. Truncated M1 inhibits fast axonal transport in squid axoplasm. In vitro translation reactions were performed using spastin plasmids engineered to produce M1-STOP spastin or M85-STOP spastin, respectively (see Material and Methods), and recombinant peptides were then perfused into squid axoplasm. A schematic depicting spastin peptides perfused in each experiment is shown above each plot. $\boldsymbol{A}$, Perfusion of M1-STOP spastin inhibits anterograde and retrograde FAT, much as seen with spastin Ncol. $\boldsymbol{B}$, Perfusion of M85-STOP spastin showed no effect on FAT. $n$ indicates the number of independent experiments. sitive to relatively moderate diminutions in microtubule-severing activity than other long axons of the body. This seems unlikely, however, because enzymes are generally expressed in excess of the levels needed (see Results). Finally, it is interesting to note that the age of onset of HSP is considerably earlier in patients who bear a function-blocking mutation on one spastin gene and a non-functional-blocking mutation on the other spastin gene (Svenson et al., 2004). Together, these observations are difficult to reconcile with a lossof-function scenario.

An alternative scenario is suggested by our observations on the distribution, expression pattern, and properties of the M1 isoform of spastin. M1 is a much less effective severing protein than M85. M1 is even less effective than $\Delta \mathrm{MIT}$, indicating that the N-terminal region of M1 more strongly inhibits the severing properties of spastin than the MIT domain enhances its severing properties. $\mathrm{M} 1$ is virtually absent from all axons at all stages of life, except for those within the adult spinal cord, in which it accounts for $20-25 \%$ of the total spastin. This is provocative because the spinal cord is the precise location of the corticospinal tracts that degenerate during HSP. These observations led us to hypothesize that disease-related mutations in spastin could generate a cytotoxic protein but only in the case of M1. In this scenario, for the spastin protein to be cytotoxic, it would have to contain the N-terminal region specific to M1 and also be functionally compromised by a mutation or by the lack of an AAA domain. To test this hypothesis, we compared the effects of truncated versions of M1 and M85 spastin lacking the AAA domain on cultures of embryonic cortical neurons. These studies demonstrated just how detrimental M1 mutants would be if they were robustly expressed during development. Neurons induced to express the truncated M1 are slower to develop, have shorter axons, and have generally less robust morphologies. Interestingly, the truncated M85 spastin (which would correspond to the mutant spastin expressed during development in HSP patients) did not cause any developmental problems in neuronal cell cultures.

To further investigate the mechanism of HSP, we tested the effects of truncated spastin M1 and M85 on FAT. Our premise that pathogenic spastin mutants could be deleterious to FAT is based on several lines of evidence linking FAT defects to HSP pathogenesis (Fink, 2003). Genetic evidence shows that loss-of-function mutations in a kinesin-1 gene (kinesin-1A, 
KIF5A) can also give rise to HSP, namely in the form of HSP termed SPG10 (Reid et al., 2002). Kinesin-1 is the principal molecular motor driving anterograde FAT (Morfini et al., 2005), and, hence, it is provocative that suppression of its functions would elicit essentially the same phenotype as mutations of spastin. Supporting this notion, analysis of SPG4-HSP patients show a length-dependent "dying back" pattern of axonal degeneration, which is consistent with deficits in FAT (Deluca et al., 2004; Morfini et al., 2007b). In our studies on squid axoplasm, perfusion of full-length spastin (M1 plus M85) showed no effect on FAT, and the same was true for the truncated M85 without the ability to sever microtubules. However, the truncated M1 polypeptide strongly inhibited FAT, indicating that it is the $8 \mathrm{kDa} \mathrm{N}$-terminal region of M1 that elicits these deleterious effects. Notably, this domain failed to show any effect on FAT when present in the context of the full-length M1 spastin protein. One possibility is that pathogenic spastin mutations induce a conformational change that results in abnormal exposure of the $8 \mathrm{kDa}$ terminal unique to M1. Consistent with this view, intragenic polymorphisms of spastin have been found within the $8 \mathrm{kDa} N$ terminus that dramatically modify the HSP phenotype (Svenson et al., 2004). In addition, spastin is known to interact with another HSP-related protein called atlastin via the $8 \mathrm{kDa}$ N-terminal region of M1 (Evans et al., 2006; Sanderson et al., 2006). Interestingly, recessive mutations in atlastin also lead to HSP (Zhao et al., 2001), suggesting that the binding of atlastin or other polypeptides to the $\mathrm{N}$ terminal of M1 could help prevent M1-induced pathology.

It has been suggested that, at least in the case of certain spastin mutations, the dysfunctional protein could associate with microtubules and impair their ability to interact with the motor proteins that fuel FAT (McDermott et al., 2003). We are skeptical of this idea because the endogenous levels of spastin expressed in neurons are probably much too low to adversely affect FAT simply by coating the microtubules. Indeed, in our experiments, truncated M1 inhibited FAT when perfused at $<100$-fold the levels of the motor proteins themselves (i.e., kinesin-1, $500 \mathrm{~nm}$ ) (Morfini et al., 2006). Although the precise mechanism by which pathogenic M1 inhibits FAT is not directly addressed by our experiments, it may be instructive that other neuropathogenic polypeptides similarly inhibit FAT by activating kinases and phosphatases involved in the regulation of molecular motor proteins (Morfini et al., 2002, 2004, 2005, 2006, 2007b; Pigino et al., 2003; Szebenyi et al., 2003). Collectively, these experimental results provide an initial set of clues that will be helpful in identifying the molecular pathway(s) by which spastin mutations may lead to axonal degeneration through a novel gain-of-function mechanism.

\section{References}

Ahmad FJ, Yu W, McNally FJ, Baas PW (1999) An essential role for katanin in severing microtubules in the neuron. J Cell Biol 145:305-315.

Ahmad FJ, He Y, Myers KA, Hasaka TP, Francis F, Black MM, Baas PW

(2006) Effects of dynactin disruption and dynein depletion on axonal microtubules. Traffic 7:524-537.

Baas PW, Qiang L (2005) Neuronal microtubules: when the MAP is the roadblock. Trends Cell Biol 15:183-187.

Baas PW, Karabay A, Qiang L (2005) Microtubules cut and run. Trends Cell Biol 15:518-524.

Brady ST, Richards BW, Leopold PL (1993) Assay of vesicle motility in squid axoplasm. Methods Cell Biol 39:191-202.

Buster D, McNally K, McNally FJ (2002) Katanin inhibition prevents the redistribution of gamma-tubulin at mitosis. J Cell Sci 115:1083-1092.

Buster DW, Baird DH, Yu W, Solowska JM, Chauviere M, Mazurek A, Kress M, Baas PW (2003) Expression of the mitotic kinesin Kif15 in postmi- totic neurons: implications for neuronal migration and development. J Neurocytol 32:79-96.

Claudiani P, Riano E, Errico A, Andolfi G, Rugarli EI (2005) Spastin subcellular localization is regulated through usage of different translation start sites and active export from the nucleus. Exp Cell Res 309:358-369.

Deluca GC, Ebers GC, Esiri MM (2004) The extent of axonal loss in the long tracts in hereditary spastic paraplegia. Neuropathol Appl Neurobiol 30:576-584.

Dent EW, Callaway JL, Szebenyi G, Baas PW, Kalil K (1999) Reorganization and movement of microtubules in axonal growth cones and developing interstitial branches. J Neurosci 19:8894-8908.

Errico A, Ballabio A, Rugarli EI (2002) Spastin, the protein mutated in autosomal dominant hereditary spastic paraplegia, is involved in microtubule dynamics. Hum Mol Genet 11:153-163.

Evans K, Keller C, Pavur K, Glasgow K, Conn B, Lauring B (2006) Interaction of two hereditary spastic paraplegia gene products, spastin and atlastin, suggests a common pathway for axonal maintenance. Proc Natl Acad Sci USA 103:10666-10671.

Evans KJ, Gomes ER, Reisenweber SM, Gundersen GG, Lauring BP (2005) Linking axonal degeneration to microtubule remodeling by Spastinmediated microtubule severing. J Cell Biol 168:599-606.

Fink JK (2003) Advances in the hereditary spastic paraplegias. Exp Neurol 184 [Suppl 1]:S106-S110.

Fink JK (2006) Hereditary spastic paraplegia. Curr Neurol Neurosci Rep 6:65-76.

Fink JK, Rainier S (2004) Hereditary spastic paraplegia: spastin phenotype and function. Arch Neurol 61:830-833.

Fonknechten N, Mavel D, Byrne P, Davoine CS, Cruaud C, Bonsch D, Samson D, Coutinho P, Hutchinson M, McMonagle P, Burgander JM, Tartaglione A, Heinzlef O, Feki I, Deufel T, Parfrey N, Brice A, Fontaine B, Prud'homme JF, Weissenbach J, Durr A, Hazan J (2000) Spectrum of SPG4 mutations in autosomal dominant spastic paraplegia. Hum Mol Genet 9:637-644.

Hartman JJ, Mahr J, McNally K, Okawa K, Iwamatsu A, Thomas S, Cheesman S, Heuser J, Vale RD, McNally FJ (1998) Katanin, a microtubulesevering protein, is a novel AAA ATPase that targets to the centrosome using a WD40-containing subunit. Cell 93:277-287.

Hazan J, Fonknechten N, Mavel D, Paternotte C, Samson D, Artiguenave F, Davoine C, Cruaud C, Dürr A, Wincker P, Brottier P, Cattolico L, Barbe V, Burgunder J, Prud'homme J, Brice A, Fontaine B, Heilig B, Weissenbach J (1999) Spastin, a new AAA protein, is altered in the most frequent form of autosomal dominant spastic paraplegia. Nat Genet 23:296-303.

Karabay A, Yu W, Solowska JM, Baird DH, Baas PW (2004) Axonal growth is sensitive to the levels of katanin, a protein that severs microtubules. J Neurosci 24:5778-5788.

Ma Y, Shakiryanova D, Vardya I, Popov SV (2004) Quantitative analysis of microtubule transport in growing nerve processes. Curr Biol 14:725-730.

McDermott CJ, Grierson AJ, Wood JD, Bingley M, Wharton SB, Bushby KM, Shaw PJ (2003) Hereditary spastic paraparesis: disrupted intracellular transport associated with spastin mutation. Ann Neurol 54:748-759.

McNally FJ, Vale RD (1993) Identification of katanin, an ATPase that severs and disassembles stable microtubules. Cell 75:419-429.

Meijer I, Hand C, Cossette P, Figlewicz D, Rouleau G (2002) Spectrum of SPG4 mutations in a large collection of North American families with hereditary spastic paraplegia. Arch Neurol 59:281-286.

Morfini G, Szebenyi G, Elluru R, Ratner N, Brady ST (2002) Glycogen synthase kinase 3 phosphorylates kinesin light chains and negatively regulates kinesin-based motility. EMBO J 23:281-293.

Morfini G, Szebenyi G, Brown H, Pant HC, Pigino G, DeBoer S, Beffert U, Brady ST (2004) A novel CDK5-dependent pathway for regulating GSK3 activity and kinesin-driven motility in neurons. EMBO J 23:2235-2245.

Morfini G, Pigino G, Brady ST (2005) Polyglutamine expansion diseases: failing to deliver. Trends Molec Med 11:64-70.

Morfini G, Pigino G, Szebenyi G, You Y, Pollema S, Brady ST (2006) JNK mediates pathogenic effects of polyglutamine-expanded androgen receptor on fast axonal transport. Nat Neurosci 9:907-916.

Morfini G, Pigino G, Mizuno N, Kikkawa M, Brady ST (2007a) Tau binding to microtubules does not directly affect microtubule-based vesicle motility. J Neurosci Res 85:2620-2630.

Morfini G, Pigino G, Opalach K, Serulle Y, Moreira JE, Sugimori M, Llinas RR, Brady ST (2007b) 1-Methyl-4-phenylpyridinium affects fast axonal 
transport by activation of caspase and protein kinase C. Proc Natl Acad Sci USA 104:2442-2447.

Pigino G, Morfini G, Mattson MP, Brady ST, Busciglio J (2003) Alzheimer's presenilin 1 mutations impair kinesin-based axonal transport. J Neurosci 23:4499-4508.

Qiang L, Yu W, Andreadis A, Luo M, Baas PW (2006) Tau protects microtubules in the axon from severing by katanin. J Neurosci 26:3120-3129.

Reid E, Kloos M, Ashley-Koch A, Hughes L, Bevan S, Svenson IK, Graham FL, Gaskell PC, Dearlove A, Pericak-Vance MA, Rubinsztein DC, Marchuk DA (2002) A kinesin heavy chain (KIF5A) mutation in hereditary spastic paraplegia (SPG10). Am J Hum Genet 71:1189-1194.

Roll-Mecak A, Vale RD (2005) The Drosophila homologue of the hereditary spastic paraplegia protein, spastin, severs and disassembles microtubules. Curr Biol 15:650-655.

Salinas S, Carazo-Salas RE, Proukakis C, Schiavo G, Warner TT (2007) Spastin and microtubules: functions in health and disease. J Neurosci Res 85:2778-2782.

Sanderson CM, Connell JW, Edwards TL, Bright NA, Duley S, Thompson A, Luzio JP, Reid E (2006) Spastin and atlastin, two proteins mutated in autosomal-dominant hereditary spastic paraplegia, are binding partners. Hum Mol Genet 15:307-318.

Sauter S, Miterski B, Klimpe S, Bönsch D, Schöls L, Visbeck A, Papke T, Hopf H, Engel W, Deufel T, Epplen J, Neesen J (2002) Mutation analysis of the spastin gene (SPG4) in patients in Germany with autosomal dominant hereditary spastic paraplegia. Hum Mutat 20:127-132.

Schickel J, Pamminger T, Ehrsam A, Münch S, Huang X, Klopstock T, Kurlemann G, Hemmerich P, Dubiel W, Deufel T, Beetz C (2007) Isoformspecific increase of spastin stability by $\mathrm{N}$-terminal missense variants including intragenic modifiers of SPG4 hereditary spastic paraplegia. Eur J Neurol 14:1322-1328.

Svenson IK, Ashley-Koch AE, Gaskell PC, Riney TJ, Cumming WJ, Kingston HM, Hogan EL, Boustany RM, Vance JM, Nance MA, Pericak-Vance MA, Marchuk DA (2001) Identification and expression analysis of spastin gene mutations in hereditary spastic paraplegia. Am J Hum Genet 68:1077-1085.
Svenson IK, Kloos MT, Gaskell PC, Nance MA, Garbern JY, Hisanaga S, Pericak-Vance MA, Ashley-Koch AE, Marchuk DA (2004) Intragenic modifiers of hereditary spastic paraplegia due to spastin gene mutations. Neurogenetics 5:157-164.

Szebenyi G, Morfini GA, Babcock A, Gould M, Selkoe K, Stenoien DL, Young M, Faber PW, MacDonald ME, McPhaul MJ, Brady ST (2003) Neuropathogenic forms of huntingtin and androgen receptor inhibit fast axonal transport. Neuron 40:41-52.

Tarrade A, Fassier C, Courageot S, Charvin D, Vitte J, Peris L, Thorel A, Mouisel E, Fonknechten N, Roblot N, Seilhean D, Diérich A, Hauw J, Melk J (2006) A mutation of spastin is responsible for swellings and impairment of transport in a region of axon characterized by changes in microtubule composition. Hum Mol Genet 15:3544-3558.

Wang L, Brown A (2002) Rapid movement of microtubules in axons. Curr Biol 12:1496-1501.

White S, Evans K, Lary J, Cole J, Lauring B (2007) Recognition of C-terminal amino acids in tubulin by pore loops in Spastin is important for microtubule severing. J Cell Biol 176:995-1005.

Wood J, Landers J, Bingley M, McDermott C, Thomas-McArthur V, Gleadall L, Shaw P, Cunliffe V (2006) The microtubule-severing protein Spastin is essential for axon outgrowth in the zebrafish embryo. Hum Mol Genet 15:2763-2771.

Yu W, Ahmad FJ, Baas PW (1994) Microtubule fragmentation and partitioning in the axon during collateral branch formation. J Neurosci 14:5872-5884.

Yu W, Solowska JM, Qiang L, Karabay A, Baird D, Baas PW (2005) Regulation of microtubule severing by katanin subunits during neuronal development. J Neurosci 25:5573-5583.

Yu W, Qiang L, Baas PW (2007) Microtubule-severing in the axon: implications for development, disease, and regeneration after injury. J Environ Biomed 1:1-7.

Zhao X, Alvarado D, Rainier S, Lemons R, Hedera P, Weber CH, Tukel T, Apak M, Heiman-Patterson T, Ming L, Bui M, Fink JK (2001) Mutations in a newly identified GTPase gene cause autosomal dominant hereditary spastic paraplegia. Nat Genet 29:326-331. 